\title{
Ha hablado Dross. Rutinas y rituales de un grupo de fans peruanos del youtuber DrossRotzank
}

\section{Diana Félix}

Universidad Peruana de Ciencias Aplicadas

dianafes360@gmail.com

RESUMEN

Esta investigación busca conocer las prácticas rutinarias y uso de contenidos audiovisuales del youtuber venezolano DrossRotzank por miembros de su club de fans en Lima, Perú. El objetivo principal es explicar por qué a los fans peruanos les gusta ver los contenidos producidos por DrossRotzank. Para resolver esta interrogante se recurrió a la etnografia digital, mediante el análisis de publicaciones en redes sociales, chats, imágenes, videos y seis entrevistas a fans destacados que narraron sus preferencias por el género del terror y situaciones paranormales o extrañas que aparecen en los contenidos audiovisuales. Entre los hallazgos se encontró que los fans comparten un culto a los contenidos del youtuber por medio de un mundo social digital compuesto de varias redes sociales y plataformas digitales en donde los participantes convergen. Este estudio analiza las razones por las cuales los fans han formado una comunidad donde mantienen el gusto compartido por el youtuber y las rutinas y rituales que ponen en práctica para hacer uso del canal de YouTube de DrossRotzank, debido a su gusto por el entretenimiento que encuentran en los contenidos audiovisuales y a la interacción directa con el youtuber vía redes sociales.

Palabras clave: etnografía digital, comunidades, internet, youtuber, rituales, fans. 


\section{Dross has spoken. A group of YouTuber DrossRotzank's Peruvian fans' routines and ritual}

ABSTRACT

This research aims to understand the routine practices and use of audiovisual content from the venezuelan youtuber DrossRotzank by members of his fan club in Lima, Perú. Therefore, the main objective is to analyse why the peruvian fans like to see the content produced by DrossRotzank. To solve this question, digital ethnography was used to analyze publications in social networks, chat rooms, images, videos, and six interviews with outstanding fans who narrated their preferences for the horror genre and paranormal or strange situations that appear in the audiovisual content. Among the findings we learned the fans share the cult for the contents of the youtuber, through a digital social world composed by several social networks and digital platforms where the participants converge. This study analyzes the reasons why the fans have formed a community where they maintain shared taste for the youtuber, and the routines and rituales they put into practice to make use of the YouTube channel of DrossRotzank, due to their taste for entertainment they find in the audiovisual content and the direct interaction with the youtuber through social networks.

Keywords: digital ethnography, communities, internet, youtuber, rituals, fans. 


\section{INTRODUCCIÓN}

Este estudio quiere demostrar por qué a un grupo de jóvenes peruanos que viven en Lima les gusta ver los contenidos audiovisuales de un youtuber. ¿Por qué formar una comunidad de fans en plataformas digitales en torno a los videos, mensajes e ideas de una sola persona con un canal en YouTube? Con más de 16 millones de suscriptores en febrero del año 2019, Ángel David Revilla, el joven venezolano, bajo el seudónimo de DrossRotzank, es uno de los youtubers latinoamericanos más conocido por sus videos sobre terror, fenómenos paranormales y datos curiosos. Su video más popular, «Las 7 cosas más asquerosas encontradas en comidas de McDonalds», tiene 39 millones de visitas. Se desprenden varias interrogantes como: ¿por qué estos contenidos audiovisuales son atractivos para los fans? ¿Cuántas prácticas sociales y rutinas se configuran alrededor de la figura del youtuber y sus contenidos? Esta investigación plantea la hipótesis: ¿el gusto compartido por un grupo de fans peruanos produce rutinas, organización y conformación de una comunidad en torno a los contenidos del youtuber DrossRotzank?

Este estudio se divide en cuatro secciones. En la primera parte se explicará la importancia de la etnografía digital como metodología para poder abordar un estudio sobre interacciones en plataformas digitales de internet, gracias a la recopilación y análisis de publicaciones en medios digitales, imágenes y videos que circulan en internet. En la segunda sección se deconstruirá la figura del youtuber para conocer su motivación por contar, compartir y difundir contenido. La tercera parte explicará la metodología utilizada para recopilar información de internet (publicaciones en redes sociales, extractos de grupos en chats online, imágenes, videos) y las entrevistas a profundidad realizadas. La cuarta parte describe los hallazgos encontrados del estudio y, finalmente, las conclusiones. 


\section{ETNOGRAFÍA DIGITAL PARA ANALIZAR MUNDOS SOCIALES DIGITALES}

Este estudio no hubiera podido realizarse sin recurrir a la etnografía digital como metodología para recopilar y analizar información sobre los sujetos y medios que se quiere conocer y entender. En el libro Digital Ethnography, los autores explican que la etnografía digital es una metodología de investigación en la que el contacto con los participantes o sujetos de estudio se da a través de medios digitales en lugar de una presencia directa; es decir, es un contacto que se establece por medio de una plataforma digital como puede ser una red social en internet (Pink, Horst et al., 2016). En la etnografía digital —explican los autores_- es posible entablar conversaciones con participantes todos los días, conocer sus prácticas cotidianas, trazar sus contenidos publicados en internet y pedirles que nos inviten a participar en sus prácticas en «social media». Sobre todo, los materiales a recopilar-como es el caso de este estudio - son audiovisuales y se encuentran en plataformas digitales de internet, como explican los autores del libro mencionado:

La escritura etnográfica puede ser reemplazada por video, fotografía o blogging. De hecho, tomar la definición abierta de O'Reilly, como punto de partida, nos ofrece una manera útil para considerar las diferencias que lo digital, en realidad, genera en nuestra práctica como etnógrafos y, así, contemplar la etnografía digital a medida que evoluciona (Pink, Horst et al., 2016, p. 3). (la traducción es nuestra).

De manera que, en la etnografía digital, el diálogo directo con los participantes no es esencial, pues se analizan los contenidos publicados, difundidos y que circulan en distintas plataformas digitales por dispositivos electrónicos. Los contenidos que los participantes publican en plataformas digitales, como webs y redes sociales, tienen la intención de dar a conocer sus ideas, gustos, malestares, miedos, etc., y a la vez, buscan tener exhibición, propagación y viralización con el fin de tener un reconocimiento en su audiencia. Por ello, la etnografía digital también busca analiza la trazabilidad y circulación de los contenidos para conocer por qué una audiencia comparte y propaga un contenido digital que, además, puede volverse mediático.

Sin embargo, esto no quiere desmerecer el contacto directo con los participantes, en la medida en que sea posible. En este caso, el estudio no solo recurrió a la recopilación y análisis de publicaciones de los participantes en redes sociales digitales o diálogos de una aplicación de chat, sino que tuvo acceso a entrevistas con los participantes que accedieron a un contacto presencial. 
Es importante mencionar, además, que la etnografía digital permite explorar mundos sociales digitales. Este estudio opta por utilizar el término de «mundos sociales digitales» en lugar de «comunidades», ya que el concepto de comunidad, como proponen los autores de Digital Ethnography, ha sido usado en un contexto antropológico y sociológico predigital para tratar de entender los mundos sociales y cómo están estructurados, conectados y enlazados entre sí (Pink, Horst et al., 2016). Estos mundos sociales, donde convergen varios participantes para la interacción y formación de relaciones, son espacios en internet y, por ende, el concepto de espacio tal como lo conocemos, que nos remite a un lugar físico, tiene la misma equivalencia, solo que en internet. «Estar en internet» es una nueva forma de habitar. Se utilizará, en esta investigación, el concepto de «localidad» para referirnos a espacios online donde convergen los participantes, como también explican Appadurai y Boellstorff.

Como explica Arjun Appadurai en el artículo «The production of Locality» del libro Modernity at Large (1996), su visión sobre la localidad se da primero de manera relacional o contextual en lugar de forma espacial o como escala:

Veo esto como una cualidad fenomenológica, constituida por una serie de vínculos entre el sentido de la inmediatez social, las tecnologías de la interactividad, y la relatividad de contextos [...] Los vecindarios, en este uso, son comunidades situadas caracterizadas por su realidad ya sea espacial o virtual y su potencial para la reproducción social (pp. 18-179) (la traducción es nuestra).

La premisa de Appadurai, entonces, busca repensar la idea de localidad vista solo como un espacio físico relacionado con un territorio. Los vecindarios (neighborhoods) en el mundo online son configurados por la interacción de quienes los conforman por afinidad entre sus miembros. Siguiendo esta idea, Pink, Horst et al. consideran que las premisas de Joshua Meyrowitz en The rise of glocality: New sense of place and identity in the global village (2005) explican cómo ya no vivimos en una localidad, sino que la «habitamos» al estar interconectados en una «global matrix», y la de Doreen Massey (2005, p. 141), la cual explica la denominación de «lugar» como «evento»o «constelación de procesos» que van cambiando constantemente a través del movimiento de las cosas, premisas importantes para definir la concepción de localidad en el ámbito digital. Sin embargo, Pink, Horst et al. (2016, p. 126) consideran que para habitar una localidad es necesario que esta sea conocida (knowable) por los participantes, ya que sus experiencias indican qué está ocurriendo y qué tipo de localidades son. 
Una propuesta similar es la de Tom Boellstorff en su estudio etnográfico sobre Second Life, una web de realidad virtual compuesta por elementos del mundo real y cuyos participantes, a través de avatares, convergen en distintas localidades dentro de este para interactuar y jugar. Boellstorff (2008) propone que los participantes de estos mundos virtuales sean llamados «residentes». Ellos pueden elegir a qué localidad pertenecer y habitar, por lo tanto, se entiende como un «lugar para jugar». A continuación, Boellstorf (2008) explica qué se entiende por «jugar» $\mathrm{y}$ «virtual», cuyas definiciones pueden tornarse un poco confusas, $\mathrm{y}$ por qué opta por acuñar el término «residentes» para los miembros de Second Life:

No hay manera de afirmar que el mundo virtual son juegos sin quedar atrapado en una definición, tan vaga, de «juego» como para incluir muchas de las vidas reales. Para algunos, pasar tiempo en mundos virtuales como Second Life significa pasar menos tiempo jugando. En esas ocasiones, durante mi trabajo de campo, cuando las personas se referían a Second Life como un juego, lo que realmente querían decir o daban por hecho era que eso era un lugar para jugar, de manera que se reflejaba la centralidad de la creatividad para entender el mundo virtual. Por estas razones, me referiré a alguien conectado a Second Life como un «residente» (un término utilizado en Second Life) en lugar de «usuario» o «jugador». (p. 22) (la traducción es nuestra).

Los estudios etnográficos digitales sobre mundos sociales y localidades nos ayudan a comprender los nuevos rituales, hábitos, relaciones interpersonales que se construyen y prácticas sociales en las cuales los humanos estamos inmersos en nuestra cotidianidad.

Entonces, la etnografía digital es sumamente importante como metodología para este estudio que busca conocer este mundo social digital formado por un grupo de fans peruanos a quienes les gusta ver los contenidos del youtuber DrossRotzank.

\section{DECONSTRUYENDO A UN YOUTUBER Y SUS FANS}

\section{La participación y rituales de los fans}

Los participantes de un mundo social digital forman parte de la organización de este a través de sus interacciones tanto en el mundo virtual como en el real (físico). Howard Rheingold (2004) explica el concepto de «red social» como una organización entre personas y los dispositivos que se realizan de manera informal y al instante, y que «cada individuo de una multitud inteligente es un 
'nodo' que tiene 'enlaces sociales'» (p. 196). Entonces, compartir contenidos, como opiniones o fanfictions, en grupos cerrados de alguna red social, poner «likes», comentar videos, etc. son acciones propias de una cultura participativa en un mundo social digital mediado por los medios de comunicación. Precisamente porque mucho contenido es compartido, viralizado, propagado en las redes sociales es que se vuelve mediático y al revés: el contenido mediático, como pueden ser series, libros o películas, por ejemplo, se convierten en objetos de culto por sus seguidores o fans y de allí emergen los fanfictions, perfiles en Facebook o Twitter de sus personajes favoritos de ficción, videos montados, etc. Siguiendo esta idea, Henry Jenkins, Sam Fort y Joshua Green (2015) también explican la cultura participativa, cuya concepción inicial servía para «describir la producción cultural y las interacciones sociales de las comunidades de fans».

Entre los años 2005 y 2008, la antropóloga Heather Horst realizó una investigación sobre medios digitales a veinticinco familias de Silicon Valley, California. En su investigación ${ }^{1}$ describe el caso de una joven de dieciséis años que era una activa escritora de fanfiction en la web fanfiction.net, donde subía contenido al igual que otros jóvenes como ella (Pink, Horst et al., 2016, p. 50). Cuenta Horst que esta joven, cuyo seudónimo era Fangrrl, empezó a crear fanfiction a los trece años, cuando comenzó a leer los libros de la saga de Harry Potter, y escribir sus propias versiones con los personajes de las ficciones que había leído y, también, visto de otras series de televisión. A los dieciséis años ganó un premio por ser escritora de fanfiction, tenía seguidores de sus ficciones y tenía una presencia en comunidades de fanfiction en internet. Heather Horst (2016), citando a Henry Jenkins (1992), explica la dinámica de los fans que utilizan los medios, en este caso digitales, para crear y producir contenidos (textos) a partir de lo que les gusta, y así, los fans van formando subculturas y cultos hacia un tema de interés para ellos. Converge, entonces, una práctica «tradicional» de los fans y las alternativas que proporcionan los medios digitales para propagar contenido (Pink, Horst et al., 2016). Esta dinámica ha llamado la atención y es estudiada por la académica:

Un grupo de académicos ha analizado la dinámica de las subculturas basadas en fans y su compromiso con los textos mediáticos; especialmente, los estudios sobre medios de comunicación y culturales de, ahora clásico, Henry Jenkins sobre las culturas de los fans (1992) que, a modo de crónica, narra cómo los fans se comprometieron, subvirtieron o se «envolvieron» con la meta y producción masiva de texto al convertirse en creadores y productores

Explicada como un caso en el libro Digital Etnography (2016). 
de formas culturales alternativas. El trabajo subsecuente ha revelado cómo, las prácticas «alternativas» empezaron a incrementarse o se volvieron más comunes con la fusión o convergencia de los medios «tradicionales»y digitales (Jenkins, 2006a). Ahora, los fans no solo consumen medios profesionalmente producidos, sino que también producen sus propios productos mediáticos, que continúan disrumpiendo las distinciones culturalmente dominantes entre las prácticas de producción y consumo (p. 50). (la traducción es nuestra).

Esto evidencia y confirma la participación de los fans y cómo al lograr agruparse y organizarse forman un mundo social digital que influye en sus ídolos e, incluso, en la industria a la que pertenecen. En Convergence culture (2006), Jenkins demuestra el importante rol de los fans que participan activamente. En su libro narra el caso de los fans de Harry Potter que tenían una voz importante y una fuerte influencia sobre los personajes de la saga que afectaban, incluso, a la industria cinematográfica. Jenkins menciona los «nuevos paisajes mediáticos, que descubren su propia voz a través su participación en las comunidades de fans, reivindicando sus derechos incluso ante poderosas entidades» (p. 208). Entonces, los fans que convergen en un mundo social digital logran intercambiar ideas, opiniones, contenidos, y así, forman comunidades organizadas en torno a un tema en común. El hecho de participar de estos mundos sociales digitales implica generar un «ritual» como parte de las prácticas sociales de los individuos (Horst y Miller, 2012), donde los dispositivos tecnológicos digitales son parte de la cotidianidad.

Un punto importante de este estudio es conocer los rituales del grupo de fans peruanos del youtuber DrossRotzank y, como se vio anteriormente, se inician por un gusto compartido entre personas que han sido partícipes, directa o indirectamente, de un evento mediático. John J. Pauly, en su artículo «Ritual Theory and The Media» (2014), explica que un evento mediático constituye una performance mediatizada que congrega una audiencia que ha vivido una experiencia compartida (Pauly, 2014, p. 179). Es decir que un evento mediático, como el lanzamiento del primer libro de la saga de Harry Potter, una boda real o la aparición de un nuevo smartphone, marcan una pauta en las rutinas de los participantes y, entonces, se generan rituales compartidos en mundos sociales organizados. Pauly afirma que «all media events disrupt the daily routines of both the media organizations that broadcast the event and the audience that witnesses it» (2016, p. 180). Asimismo, Pauly cita a Nick Couldry (2003) cuando se refiere a que el evento mediático no solo expresa un orden social, sino que lo naturaliza. Los rituales mediáticos 
producen una circulación de textos como imágenes, discursos e ideas (2014, p. 187), los cuales generan que hagamos uso de ellos. En el caso del grupo de fans peruanos de DrossRotzank, muchos se enteraron de la existencia del youtuber navegando por internet hasta julio del año 2016. En ese año, el youtuber llegó por primera vez a Lima para presentar su segundo libro, llamado Festival de la blasfemia. Ese evento mediático congregó a fans que no sabían que había tantos en Lima. Eso motivó a la creación del primer club de fans de DrossRotzank en Facebook. Los fans generan rituales y rutinas al realizar prácticas habituales o cotidianas, como crear o compartir contenido en su mundo social digital. La acción de ingresar todos los días a ver un video colgado por el youtuber o comentar sobre un video en el fanpage del youtuber genera rituales y rutinas que dan sentido a un grupo de personas reunidas con un gusto compartido.

\section{Dinámica del youtuber DrossRotzank}

YouTube es una plataforma creada en junio del año 2005 con el objetivo original de compartir videos con otros participantes y así formar «un sitio de cultura participativa» (Burgess y Green, 2009, p. 7). En la actualidad, como explican Jean Burgess y Joshua Green, celebra y representa el logro de la democratización de la producción cultural y la interconectividad global. YouTube es una entidad propagadora y configuradora de la cultura pop, a través de nuevos formatos narrativos y modelos de negocio: tutoriales, videos sobre emprendimientos, blogs, campañas de marketing de compañías, etc. (Burgess y Green, 2009). Asimismo, el investigador Jie Gu, en su estudio From watching yourself to broadasting and back again: negotiating dual roles of new media audiences of Youtube (2014), explica que el youtubing (término acuñado por el autor) es una práctica social con la cual los participantes tienen la motivación individual de subir y compartir la vida cotidiana (everyday life). En este estudio, se considera a YouTube una red social en internet:

De YouTube se ha desarrollado una práctica independiente llamada youtubing en nuestro mundo social. Esta práctica de youtubing es característica de personas que suben videos y comparten actividades. Luego, al ver el uso que las personas hacen de YouTube como un momento que ocurre en la práctica de youtubing, podemos estudiar el uso que las personas le dan a YouTube a través de su inmersión en la práctica de youtubing. En consecuencia, los usuarios de YouTube ya no son más interpretados como productores, consumidores o usuarios, sino como actores competentes e informados quienes llevan a cabo la práctica de youtubing en su vida diaria. (p. 3) (la traducción es nuestra). 
La propuesta sobre la práctica de youtubing es interesante, porque nos ayuda a definir quiénes la realizan y de qué manera. Su estudio demostró que existen cuatro tipos de participantes que convergen en YouTube y realizan distintas acciones. Así, dos tipos de participantes realizan youtubing por estos motivos: (i) genera una extensión hacia otras prácticas; (ii) la práctica de youtubing atraviesa y deriva a otras prácticas sociales. Resulta importante tomar en consideración estos hallazgos de $\mathrm{Gu}$, porque el hecho de realizar prácticas sociales cuyo origen fue ver un video en YouTube indica que un sujeto aplica una serie de actividades, rutinas y rituales a partir de un contenido mediático visto en una red social. No es ver o compartir un simple video, sino llevarlo a la vida cotidiana, a la realidad de cada sujeto y a sus propias acciones en el mundo social que habita físicamente, y también en un mundo social digital creado. Crear, propagar, viralizar, replicar ideas que son compartidas por una determinada audiencia tiene una agencia en las actividades de los participantes.

Quienes tienen un canal de YouTube lo hacen porque quieren que sus ideas lleguen a una audiencia y saben que influirán en las ideas y acciones de sus seguidores; por ello, la práctica rutinaria de «subir» contenidos temáticos al canal con una frecuencia determinada, para que sean compartidos y viralizados por su audiencia. Así es como nace la figura del youtuber. Burgess y Green (2009) explican que la motivación de los youtubers se da por «the promise that talented but undiscovered youtubers can make the leap from their 'ordinary worlds' to the bona fide 'media world' is firmly embedded in YouTube itself» (p. 23).

De igual manera, Burgess y Green explican que el éxito de los youtubers se debe a que son conocidos y amenos para la audiencia. Los youtubers conocen a su audiencia, les solicitan retroalimentación sobre sus contenidos y les piden comentarios sobre los videos. La interacción con sus fans y la performance que emplean en sus videos resulta atractiva. Esto genera que los seguidores o fans construyan un mundo social, sigan al youtuber por otras redes sociales alternas a YouTube, opinen sobre los contenidos, sugieran temas de discusión, organicen eventos, busquen interactuar con el mismo youtuber y vean videos.

Todas estas acciones son prácticas que se convierten en rituales y rutinas realizadas por el youtuber y sus fans. Esto merece una mención sobre el placer que genera crear, consumir o propagar contenidos audiovisuales y mediáticos. ¿Por qué nos gusta ver videos en YouTube? ¿Qué le encontramos de placentero? Mark Allen Peterson explica en Anthropology and Mass Communication: Media and Myth in the New Milennium (2014) que existe una tipología del placer, al que divide en los siguientes componentes: estético, lúdico, moral, escapista, 
transgresor, fático, socialidad imaginada y nostálgico. Entonces, de esta idea se desprende que la práctica rutinaria y el ritual que un sujeto crea al ver contenidos audiovisuales en YouTube se debe a que le gusta, lo atrae y le da placer. La audiencia reserva y dedica un tiempo y un espacio, entre sus actividades cotidianas, para ver, comentar, compartir y propagar los contenidos mediáticos de un youtuber en internet, así como replicar y demostrar afinidad con sus ideas en otras acciones fuera del mundo social digital.

Pero ¿quién es el youtuber DrossRotzank? ¿Por qué tiene más de 16 millones de suscriptores de su canal de YouTube? ¿Cómo ha logrado que sus videos publicados cada día o cada dos días puedan viralizarse hasta sobrepasar el millón de visitas?

DrossRotzank, cuyo nombre real es Ángel David Revilla, es venezolano. Su primera plataforma en internet donde colgaba contenido apareció en el año 2006, mediante un blog llamado El diario de Dross; sin embargo, fue en junio del año 2009 cuando creó su canal de YouTube llamado DrossRotzank. Los primeros videos que propagó trataron acerca de videojuegos. Poco a poco el contenido subido empezó a exponer temas sobre terror, actividades paranormales, sucesos insólitos o hechos históricos grotescos y tenebrosos. La frecuencia con la que sube videos a su canal de YouTube es de tres veces por semana, normalmente, o cuatro videos cada día en una semana. Las visitas superan las 100000 en el primer día de haberse subido el video. DrossRotzank menciona en una entrevista que él creo su canal de YouTube para contar historias porque lo que quería, en el fondo, era escribir ficción ${ }^{2}$.

La fama obtenida por su canal de YouTube fue de gran ayuda para que las editoriales consideren su manuscrito para la publicación, y el hecho de recibir el apoyo de fans hizo más atractiva la posibilidad de publicación. Luna de Plutón, su primer libro, fue vendido en varios países de Latinoamérica. En el año 2016, cuando presentó su segundo libro de ficción El festival de la blasfemia por primera vez en Lima, muchos fans peruanos del youtuber pudieron congregarse en un lugar para verlo. El evento mediático del año 2016 -la presentación de su segundo libro en la Feria Internacional del Libro de Lima 2016 y en el Horror Fest- fue decisivo para que los fans se conozcan y sepan que, al igual que ellos, existen otros peruanos que viven en Lima a quienes también les gusta DrossRotzank y sus contenidos audiovisuales y mediáticos. No estaban solos. A partir de ese momento, un grupo de fans peruanos deciden formar un club de fans en torno a DrossRotzank en el Perú.

2 Entrevista en diario Publimetro Perú: https://publimetro.pe/entretenimiento/noticia-drossrotzank-mi-canal-ha-dejado-escuela-video-72628 


\section{METODOLOGÍA DEL ESTUDIO}

La etnografía digital es de suma importancia para la realización de este estudio. Se exploraron los contenidos audiovisuales del DrossRotzank publicados en sus distintas redes sociales: YouTube, Facebook, Twitter e Instagram para conocer sus temas de interés: terror, sucesos paranormales, situaciones insólitas, historias de horror basadas en hechos reales. También la interacción que mantiene con sus seguidores o fans: respuestas a comentarios de publicaciones, «likes» a comentarios, retweets en Twitter, agradecimientos en sus videos a los fans que le escriben a su mail, donde le envían información y sugerencias sobre temas paranormales y de terror, así como música para ambientar sus videos. Asimismo, se recurrió a la exploración y el análisis de las publicaciones del grupo de fans peruanos miembros del club de fans en Facebook: DrossRotzank FC Perú - Grupo Oficial (grupo cerrado) y del grupo en WhatsApp llamado DrossRotzank Perú $\bullet$.

Es importante señalar que, para conocer a mayor profundidad las rutinas y rituales de los fans, se realizaron seis entrevistas a profundidad a los fans del grupo cerrado de Facebook. Se contactó, vía Messenger de Facebook, a los administradores y fans que publicaban más contenido en el grupo, para solicitar entrevistas presenciales. De los fans solicitados, solo tres (entre ellos, un administrador del grupo) eran también miembros del grupo privado en WhatsApp y accedieron a las entrevistas presenciales y grabadas en video para este estudio. Una limitación fue no poder entrevistar a más fans del club de fans en Facebook, debido a que dos personas más no respondieron los mensajes por el chat de Messenger y una no quiso ser entrevistada. Se buscó tener contacto con la creadora del club de fans en Facebook, pero no se pudo realizar la entrevista por ser menor de edad y no se obtuvo el permiso de sus padres para acceder a la entrevista presencial. Los otros tres fans entrevistados solo pertenecían al grupo cerrado de Facebook. También se conversó, brevemente, con Victoria Hidalgo, miembro de la organización del evento Horror Fest 2016, que comentó ser fan de DrossRotzank y que mantenía contacto directo con él por una afinidad al género del terror y lo insólito.

Cada entrevista contó con la autorización de los entrevistados y duraron entre veinticinco y cuarenta minutos. Las locaciones fueron distintas (parques, restaurantes, hogares) y en diferentes fechas entre setiembre de 2016 y noviembre de 2017. Cuatro de los entrevistados fueron contactados individualmente vía chat y dos fueron contactados a través de un cuarto entrevistado por recomendación. 


\section{HALLAZGOS DE LA ETNOGRAFÍA DIGITAL Y ENTREVISTAS A FANS DEL YOUTUBER DROSSROTZANK}

Los seis entrevistados fueron jóvenes entre 20 y 35 años: tres mujeres y tres hombres que viven en Lima Metropolitana. Fueron entrevistados entre setiembre de 2016 y noviembre de 2017. Los más jóvenes (20, 21 y 22 años) son dos mujeres y un varón que actualmente son estudiantes de educación superior. Los otros dos varones y una mujer ( 29,31 y 35 años) son profesionales que trabajan. Un hallazgo interesante fue el acceso que tenían a dispositivos electrónicos y móviles. Todos los entrevistados tenían acceso a smartphones y computadoras con internet. Así podían conectarse e interactuar entre ellos.

La primera pregunta que se realizó a los seis entrevistados fue: «¿Cómo y cuándo encontraste a DrossRotzank?» Cuatro respondieron que encontraron el canal de DrossRotzank mientras navegaban en internet y buscaban videos sobre temas de terror, horror, misterio o fenómenos paranormales. Realizaban youtubing (Gu, 2014) al buscar contenidos entretenidos, mas no con el propósito de crear contenidos. Dos testimonios afirmaron que se lo recomendaron o que un amigo les contó que existía un canal de YouTube que veía habitualmente temas de terror o paranormales. Así, un testimonio explica cómo encontró el canal de YouTube de DrossRotzank:

Yo soy un apasionado por los temas de terror y horror. A mí me gusta muchísimo lo que tenga que ver con el terror, el suspenso, ¿no?, lo desconocido, en general. Y bueno, pues, averiguando en internet sobre libros y películas, $\mathrm{y}$ en internet también buscaba videos de terror, y pues, Dross es un youtuber que se especializa, de alguna forma, en subir este tipo de videos de terror, de misterio. Un día, no recuerdo muy bien cuándo, pero aproximadamente hace tres años, estaba navegando en internet, en YouTube y me crucé con su canal. Recuerdo que el primer video que vi fue «Diez hechos inexplicables» o algo así, pero desde ahí, desde esa fecha, estoy enganchado a su canal (testimonio 1, fecha: 16 de setiembre de 2016).

Los demás entrevistados narran que lo que los «enganchó» con DrossRotzank fue la información verídica (que fue comprobada como real e histórica) de sus videos como los Top 7 (ranking de siete casos curiosos sobre temas paranormales, terror o raros actuales e históricos) y las historias de terror. Otro dato importante: a todos los entrevistados les atrae su estilo narrativo y la entonación de su voz en sus videos. Todos los videos del canal de YouTube DrossRotzank son con voz en off (excepto cuando realiza transmisiones en vivo) y con imágenes de apoyo o 
extractos de videos reales encontrados en internet. Las palabras típicas que utiliza el autor para narrar hechos, su voz y sus bromas y lisuras: «coño», «verga» son atractivos para los participantes, así como para sus seguidores, que comentan en los videos de DrossRotzank (la lisura típica de Dross es: «ißCoooñooooo!!). Así lo comentan los participantes:

[...] así navegando encontré el canal, pues, y vi que [el Dross] tenía una buena actitud al momento de hablar, tenía como que ese «gancho» que te jala al momento de hablar, al hacer esas bromas, a veces con lisuras, pero lisuras que a mí me entretenían demasiado, y entonces empecé a ver sus videos. En una noche me quede viendo seis o siete videos (testimonio 3, fecha: 28 de setiembre de 2016).

La primera vez que vi el Dross, más allá del tema del que pudiera estar viendo, del top, por ejemplo, el primer video que vi fue un top sobre las siete películas que te pueden destrozar la cabeza, o sea, el top es buenazo, el tema es buenazo, y aparte te da películas y te sorprendes, pero lo que más me atrajo fue su voz y la forma en que contaba los videos, te generaba ese enigma que te metía más en el tema raro y aparte te generaba la pregunta de quién es este pata que cuenta estas cosas y su voz es medio rara, es peculiar su voz, no es una voz normal, porque tiene un dejo raro y es como que medio oscura. Yo me imaginaba que era un viejo medio raro, no sé, que vivía en una casa en un bosque y aparte sus peculiares frases ya conocidas, su rico vocabulario que tiene, por ejemplo cuando dice: «inenarrable» o cuando dice «hórrido», son palabras que se quedan marcadas ya desde la primera vez que lo vi (testimonio 2, fecha: 17 de setiembre de 2016).

Normalmente, como él dice, él investiga cosas que ya están en internet y él hace lo que le parece interesante, obviamente, cuando algo me parece muy interesante sobre algo que ya explicó, intento buscar [información] sobre los links que él deja, porque él comenta, por ejemplo, mujer fue vista volando, algo así, acá te dejo los links, voy al link, leo y voy viendo los comentarios. Algunos dicen que sí es real, que no es real o que es montado y yo... la verdad a veces me quedo con la duda, pero intento creer que la búsqueda de información del Dross es la verídica y trato de quedarme con la que él me da (testimonio 4, fecha: 2 de octubre de 2016).

DrossRotzank se encuentra en contacto con sus fans, a quienes agradece en sus videos por la información novedosa que le envían a su mail. Interactúa con ellos en redes sociales, como ya se describió anteriormente; sin embargo, un hallazgo es que este youtuber, en el año 2016, era activo y dueño de un mundo en la realidad virtual Second Life, espacios digitales donde también se encontraba 
con sus seguidores. Los tres fans que participaban del grupo de WhatsApp sabían que también se podía interactuar con DrossRotzank por medio de su mundo en Second Life. Es interesante, entonces, encontrar que el mundo social digital de estos fans incluye diversas plataformas digitales de interacción y, por ende, un tiempo dedicado a conectarse a dispositivos con internet.

Figura 1. Captura de pantalla de tweet de Youtuber en twitter. Esta captura de pantalla fue compartida en el grupo de Whatsapp del grupo de fans peruanos

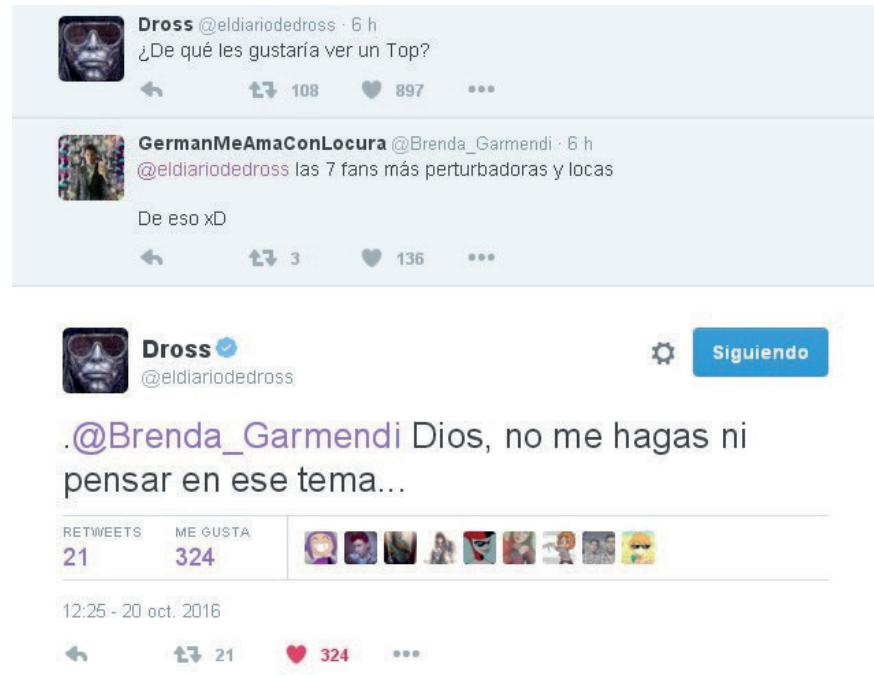

Fuente: Recuperado de twitter @eldiariodedross el 20 de octubre de 2016.

Si bien los entrevistados valoran la información que Dross utiliza en sus videos, cuatro entrevistados comentaron que veían el canal de YouTube por mero entretenimiento, mientras que los otros dos entrevistados (31 y 35 años) veían los videos por el material curioso y aprendían de los datos, ya que luego cruzaban información para confirmar si los videos, principalmente los de las temáticas del Top 7, tenían información verdadera con referencia a los hechos científicos e históricos de terror. Sin embargo, uno de los entrevistados que valora la información documentada y verídica mencionó que depende del criterio de los seguidores creer o validar la información que presenta el youtuber en sus videos:

Yo lo encontré, yo lo encontré. Estoy seguro que nadie me recomendó, yo lo encontré por YouTube, buscando, mirando, y hace cuatro años que lo estoy siguiendo y su peculiaridad y su forma de narrar es atrapante $[\ldots]$ estaba 
buscando información de la deep web y allí apareció el Dross, sobre todo invita la curiosidad a seguir viendo cosas que él cuenta, casos que han sucedido que uno piensa que no es posible, pero son cosas que tienen que estar documentadas, pero él las cuenta muy bien y a veces pueden ser reales o fake, pero ya es criterio de cada uno (testimonio 5, 10 de diciembre de 2016).

Asimismo, el gusto por datos insólitos sobre ciencia, historia y horror, videojuegos, historias de terror (temáticas recurrentes en los videos de DrossRotzank) es una característica común entre los entrevistados. Otra similitud que este estudio encontró fue la rutina que estos seguidores cumplen: normalmente ven los nuevos videos subidos por DrossRotzank en la noche. En algunas ocasiones, ven los videos apenas llega la notificación (al smartphone o en la computadora) que puede ser en la mañana o tarde, pero todos mostraron su predilección por ver los videos por la noche o la madrugada, pues tienen menos ocupaciones y más tiempo libre. Los ven antes de dormir. Por algo, al final de cada video, el mensaje de DrossRotzank de cierre es: «Te ha hablado Dross y te deseo buenas noches».

Hay unas notificaciones que te llegan de que acaba de colgar un video. Si lo cuelga el día lunes, lo puedo ver el mismo lunes, a más tardar al siguiente día, obviamente no en el horario de trabajo, pero siempre en las noches. Por las noches, siempre lo vemos (yo y mi enamorado). Termino mi día viendo el Dross (testimonio 6, 17 de noviembre de 2017).

Otro hallazgo importante fue conocer con quién veían o compartían estos contenidos audiovisuales. La entrevistada 6 , además, indicó que ve los videos del youtuber con su pareja como parte de su rutina, y luego lo comentan o buscan información en la web para confirmar los datos verídicos o históricos como parte de la narrativa del video (gusto compartido). Otro entrevistado (5) también afirma ver los videos con su pareja porque a ambos les gusta y también lo ven por la noche porque sus contenidos «asustan» y «en la noche dan más miedo». A veces, el entrevistado ve los videos solo. Sin embargo, los demás entrevistados afirmaron que ven los videos solos la mayoría de veces. Los tres fans que pertenecen al chat de WhatsApp comentan en ese grupo o en las demás redes sociales sobre los recientes videos que sube el youtuber y existe un intercambio de comentarios con los demás fans del grupo. Es interesante encontrar que la acción de ver los videos del youtuber es solitaria en varios casos, para luego compartir ideas o sensaciones sobre el video en el mundo social digital creado por los mismos fans. Es en ese mundo donde pueden compartir sus gustos por los contenidos del youtuber. 
Los fans están suscritos al canal de YouTube y a otras redes sociales de DrossRotzank. Reciben la alarma de notificación de cada video nuevo y lo consumen de noche y, por lo menos, una vez por semana. Califican y comentan los contenidos de los videos y los contenidos audiovisuales que el youtuber comparte en sus redes sociales. Recomiendan a su entorno (más cercano) visitar el canal de DrossRotzank para explorar, a través de los videos, temas «insólitos», «perturbadores», «terror», «casos paranormales» y «Top 7» sobre temas desconocidos o datos curiosos. Sin embargo, este estudio encontró que hay dos tipos de fans del youtuber: los que buscan tener un contacto directo con DrossRotzank a través de distintas plataformas para tener un reconocimiento por el youtuber y los que se consideran fans sin buscar un contacto directo.

\section{Los fans que no buscan un contacto directo con DrossRotzank}

Tres de los fans entrevistados (los tres mayores) no buscaban tener un contacto directo con el youtuber, no eran parte de grupo de chat de WhatsApp y tenían poca interacción en el grupo cerrado del club de fans de Facebook, aunque sí estaban atentos a las noticias sobre las giras y actividades del youtuber para comentar y compartir. Aun así, se consideraban grandes fans porque seguían a DrossRotzank en sus distintas redes sociales y mantenían sus rutinas para ver sus videos y otros contenidos audiovisuales.

La manera en que ellos interactúan con Dross es a través de un «like» a sus videos o un comentario en la sección de comentarios de sus videos de su canal de YouTube o en otras redes sociales. No consideran tan importante o prioritario que el youtuber les responda. Si bien DrossRotzank nunca les ha dado un «retweet» o «like» o respondido un mail, no dejan de ser sus fans, comprar sus libros y difundirlos entre personas que no sabían quién era DrossRotzank.

\section{Los fans que interactúan entre ellos y con DrossRotzank}

Estos son los fans más activos que participan en varias redes sociales digitales. Son los más jóvenes (20, 21 y 22 años) y los estudiantes (en noviembre del año 2016). El grupo se dividió en dos: «Dross Rotzank FC Perú - Grupo Oficial» (primer grupo formado) y «DrossRotzank Perú Oficial único grupo oficial» (los tres entrevistados más jóvenes formaron este último grupo en Facebook). El primer grupo de fans en Facebook fue creado a partir del evento mediático del youtuber: su primera visita a Lima para presentar su segundo libro en dos locaciones (Feria 
Internacional de Libro de Lima y Horror Fest). Ningún entrevistado pensó que había tantos fans del youtuber en el Perú, o al menos en Lima. No se conocían entre sí hasta que asistieron a ambos eventos o a uno de ellos. La autora de este estudio realizó un video el día de la presentación en el mes de julio de $2016^{3}$.

A partir de ahí, se formó el mundo social digital alrededor de DrossRotzank con la creación del club de fans vía redes sociales. En ese espacio virtual convergen los fans que no se conocían antes, pero a partir de entonces sí tienen con quién compartir un mismo gusto. Ese mismo año en setiembre fue creado el grupo de WhatsApp ${ }^{4}$ con el objetivo de discutir y compartir opiniones y preferencias por los contenidos del canal de YouTube, admiración, identificación y posibilidad de contacto directo con el youtuber. En este grupo de WhatsApp, los más de veinte miembros compartieron acciones que pensaban a hacer para involucrarse y conocer a Dross y su universo: viajar a Argentina o compartir fanfictions sobre los personajes de los libros del Dross ${ }^{5}$. Un hallazgo interesante es que son las mujeres (jóvenes y adolescentes) quienes más interactúan en el grupo, compartiendo fotos o fotomontajes, fanfiction y retweets del youtuber con los fans en otras plataformas digitales. Los pantallazos de las interacciones se comparten en el chat.

Asimismo, es importante observar cómo han mantenido una organización con jerarquías y roles en el grupo de WhatsApp y de Facebook; por ejemplo, hay administradores del grupo, quienes tienen el rol de aceptar el ingreso de nuevos fans a estos grupos cerrados, proponer posibles reuniones presenciales, actividades que involucren contactos directos con el DrossRotzank en la web, preguntar si asistirán a algún evento donde esté presente el youtuber o una iniciativa interesante, como organizarse para enviarle un obsequio al youtuber por su cumpleaños. Estas son acciones que se entremezclan entre las de su mundo social digital y las de su mundo social terrenal y cotidiano.

En el caso de estos tres entrevistados, ellos se conectaban al WhatsApp entre las 10 p.m. y las 1 a.m. de lunes a viernes y también los fines de semana, ya sea para comentar un video que habían visto en ese momento o algún dato que querían

Ver link del video de la presentación de DrossRotzank en Lima, julio de 2016: https://www.youtube.com/ watch? $\mathrm{v}=\mathrm{T} 5 \mathrm{IcS} 8 \mathrm{nEIE} 4 \&$ feature $=$ youtu.be

4 En esta investigación, parte de la etnografía digital comprendió interactuar con los miembros del grupo de WhatsApp y en el mismo grupo desde setiembre hasta diciembre de 2016. No se continuó en el año 2017, por lo que no se sabe si el grupo sigue en actividad.

5 Hasta el año 2016, el youtuber DrossRotzank contaba con dos libros publicados por el Grupo Planeta: Luna de Plutón y El festival de la blasfemia. 
agregar para discutir. Asimismo, ese espacio sirvió también para discutir detalles de su vida cotidiana sobre sus quehaceres en sus centros de estudios, compartir bromas o memes sobre el youtuber que encontraban en internet o generaban, o para avisar que Dross estaba en vivo o streaming en alguna plataforma digital: YouTube, Younow o Second Life (cuando en el año 2016 mantenía un SIM o lugar en esa plataforma de realidad virtual). El tema de los memes y el humor es muy importante, porque el mismo Dross hace uso del humor en algunos de sus videos e interpreta a personajes como «El troll» $\mathrm{y}$ «Estela Conchaseca» o su novia (a la que nunca se le ha visto), llamada «La gorda», que a estos entrevistados y a los miembros del chat en WhatsApp les divierte.

Otro hallazgo encontrado en el grupo fue el lenguaje utilizado y la familiaridad con la que los miembros, principalmente las mujeres, se refieren al youtuber al momento de compartir fotos, fotomontajes o memes: «Drossy», «Drosito» o «el Dross». Los fans narraron haber aprendido frases o vocablos que el youtuber repite constantemente, como «hórridamente», «inenarrable», «búscame en mis redes sociales para estar en contacto», «quiero leer tus ideas», «te ha hablado Dross y te deseo buenas noches». Los fans entrevistados repiten estas frases y términos y así identifican a otros fans de Dross, de manera que esta práctica alimenta y consolida este culto al youtuber.

Los memes, las imágenes, los videos, el uso de un lenguaje propio de los fans compartidos entre ellos y con fans fuera de los grupos cerrados son una búsqueda para destacar y ser reconocidos ante la audiencia en redes sociales. Nell Haynes, en su libro Social Media in Northern Chile (2016), analiza a un grupo de jóvenes de una ciudad llamada Alto Hospicio que comparten memes, mensajes e imágenes sobre ellos mismos con el objetivo de exhibirse como personas austeras para consolidar su identidad: austero y nada ostentoso con prácticas u objetos (ropa, aparatos electrónicos) costosos. En este caso, los fans de DrossRotzank buscar exhibirse y demostrar que conocen los contenidos y al youtuber a través de la circulación de memes, imágenes, videos y mensajes en redes sociales del youtuber, las fanpages, los grupos cerrados (como los dos clubs de fans) y sus propias plataformas digitales.

\section{CONCLUSIONES}

Esta investigación ha demostrado que la etnografía digital como metodología ha sido vital para la recopilación de información y contacto con los sujetos para lograr este estudio. Repensar los espacios y localidades (Appadurai, 1996) es importante 
para entender que la interacción de personas que van formando subculturas que, a la vez, producen cambios en la cotidianidad terrenal. Una de las conclusiones sobre la metodología aplicada a este estudio es que acceder a los mundos sociales digitales demanda tiempo y paciencia. Contactar a los fans vía redes sociales fue una tarea en la que se debía esperar, dado que quien contactaba (la autora) era una persona extraña que enviaba un mensaje para solicitar una entrevista. Asimismo, se buscó la participación en un mundo social digital para entender las rutinas y rituales de los fans. La confianza que se estableció con los entrevistados se dio por la sinceridad sobre la realización de este estudio. Se logró hacer seis entrevistas cuyo primer contacto fue por chat online. Dos entrevistados se convirtieron en informantes y fueron de gran ayuda para poder llegar a los demás, vía chat.

Sobre el mundo social digital creado por los fans y su organización para proponer y realizar actividades, este estudio concluye que existe un momento y un espacio liminal en el que las acciones del mundo social digital se entremezclan y se convierten en acciones que irrumpen en su cotidianidad terrenal. Por ello, fue importante ubicar estas acciones como grupo organizado y fuera de lo virtual. Existe un punto en el que se atraviesa de un mundo social a otro, y las acciones que involucran al youtuber tienen implicancias y repercusiones en su cotidianidad, como recomendar el canal de DrossRotzank a amigos que no lo conocen, participar en el chat de WhatsApp o en el grupo de fans en Facebook, repetir y propagar los videos y frases del youtuber, organizar la compra de un regalo o asistir a eventos que tienen que ver con DrossRotzank.

Se desprende del estudio, asimismo, que el youtubing ( $\mathrm{Gu}, 2014)$ puede ser una actividad solitaria o muy personal. Si bien dos entrevistados ven los videos en compañía de sus parejas por las noches antes de dormir, como parte de la rutina, los demás entrevistados, principalmente los tres fans que buscan tener un contacto directo con el youtuber, ven los contenidos audiovisuales solos. Debido a que los contenidos del youtuber se difunden desde sus propios canales y no se transmiten por señal abierta en televisión (una audiencia masiva), solo son encontrados y seguidos por fans que tienen un determinado gusto. Al ser un gusto muy particular (terror y fenómenos paranormales o insólitos), los fans los ven cuando están solos y únicamente pueden compartir con sus pares en un mundo social digital. Han encontrado en esta localidad un espacio virtual para compartir con los demás miembros sus intereses y gustos similares. Dentro de ese mundo social digital ya no están solos.

De lo anterior se llega a otra conclusión: la identificación y afinidad del grupo de fans peruanos con las ideas del youtuber DrossRotzank son por el uso de datos 
reales y comprobables en sus contenidos audiovisuales y porque consideran estos contenidos mediáticos como entretenimiento. El youtuber cuestiona y critica ideas y datos que aparecen en los videos que emite y eso resulta placentero para los fans. Los fans también cuestionan sucesos de su propia realidad, sucesos políticos y actuales en el mundo, en su país y en su ciudad, el mundo social digital se convierte en un espacio placentero. Un escape de una realidad y contenidos en medios masivos (televisión, prensa, radio) que no son de su agrado y, por ello, se refugian en la propuesta del youtuber. Se concluye que los participantes atraviesan por un proceso de dislocación (Appadurai, 1990) de su espacio cotidiano para permanecer en el espacio virtual. Los mundos sociales digitales resultan atractivos y cómodos para permanecer, al compartir con personas similares entre sí.

El estudio también concluye que la circulación de los contenidos por internet es, en su mayoría, hecha por fans motivados por el youtuber que busca que sus contenidos sean propagados y extender su audiencia. Esto ha generado que muchos fans tengan roles de «evangelizadores de contenidos» y se organicen en grupos de fans para realizar eventos u otras actividades que generen una mercancía y los conviertan en empresarios de sí mismos y de sus modelos de negocio. Es el caso de los administradores de los grupos en redes sociales y fans que cumplen roles, o de la organizadora del evento Horror Fest 2016, quien es una fan del género del terror y de DrossRotzank; por ello, lo invitó al evento.

Finalmente, los rituales y rutinas practicadas por este grupo de fans peruanos se convierten en hábitos. Como explica Nick Couldry (2003), los rituales mediáticos son replicados por otros. Las acciones que el youtuber realice en sus plataformas digitales o las ideas que propague, serán replicadas y difundidas. Así, encontramos el hábito de ver los videos de noche, repetir sus frases y vocablos propios, ingresar a sus redes sociales para buscar interacción con el youtuber, seguir sus recomendaciones y compartir los contenidos con los demás. Asimismo, la circulación y calificación de contenidos audiovisuales realizada por los fans, es también parte del ritual. Cada fan, asimismo, tiene su propio ritual para ver los videos que comprende un tiempo, espacio o una acción determinada. Por ejemplo: ver un video un domingo por la noche, solo, en la cama de mi habitación, mientras disfruto de la cena.

La construcción de un culto a un youtuber a través de estos rituales y rutinas demuestra la influencia del entretenimiento como un género valorado por la audiencia. Millones de personas tienen cada día más acceso a internet y a dispositivos electrónicos, lo que propiciará la formación de más mundos sociales digitales, y es el entretenimiento un género que da placer, distrae y desvía la 
atención a conflictos o situaciones que requieren concentración o soluciones. Estudiar los rituales y las rutinas de los fans de un mundo social digital en torno a un youtuber es, entonces, necesario para entender sus repercusiones y consecuencias en el mundo cotidiano terrenal y viceversa.

\section{REFERENCIAS BIBLIOGRÁFICAS}

Appadurai, Arjun (1990). Disjuncture and Difference in the Global Cultural Economy. Theory, Culture \& Society, 7(2-3), 295-310. https://doi. org/10.1177/026327690007002017

Appadurai, Arjun (1996). Modernity at Large. Cultural Dimensions of Globalización. Minneapolis: University of Minnesota Press.

Boellstorff, Tom (2008). Coming of Age in Second Life. An Anthropologist explores the virtually human. Princeton: Princeton University Press. https://doi. org/10.1515/9781400874101

Burgess, Joshua y Joshua Green (2009). Youtube. Online Video and Participatory Culture. Cambridge: Polity.

Couldry, Nick (2003). Media Rituals. A critical approach. Londres: Routledge. https:// doi.org/10.4324/9780203986608

Gu, Jie (2014). Participating in Youtubing practice: towards a practice perspective to understand user participation motivations. Recuperado el 15 de diciembre de 2016 de www.media-anthropology.net

Haynes, Nell (2016). Social Media in Northern Chile. Londres: University College London Press. https://doi.org/10.2307/j.ctt1g69xv2

Horst, Heather y Daniel Miller (2012). Digital Anthropology. Londres: Berg.

Jenkins, Henry (2006). Convergence culture. Nueva York: New York University Press.

Jenkins, Henry, Sam Ford y Joshua Green, (2015). Cultura transmedia. Barcelona: Gedisa.

Massey, Doreen (2005). For space. Londres: Sage Publications.

Meyrotwitz, Joshua (2005). The rise of glocality: New sense of place and identity in the global village. En Kristof Nyiri (ed.), A Sense of Place. The global and the local in Mobile Communication (pp. 21-30). Viena: Passagen Verlag.

Pauly, John (2014). Ritual Theory and the Media. En Robert S. Fortner y Mark Fackler, The Handbook of Media and Mass Communication Theory (pp. 172-189). Chichester, West Sussex, UK: John Wiley \& Sons, Inc. 
Peterson, Mark Allen (2005). Anthropology and Mass Communication: Media and Myth in the New Millenniun. Oxford: Berghahn.

Pink, Sarah, Heather Horst et al. (2016). Digital Ethnography: Principles and Practice. Londres: Sage Publicactions.

Rheingold, Howard (2004). Multitudes inteligentes. La próxima revolución social. Barcelona: Gedisa.

Snickars, Pelle y Patrick Vonderau (2010). The youtube reader. Estocolmo: National Library of Sweden. 